Jurnal Pendidikan Dasar, 6 (1) Juni 2018

\title{
PENGARUH MODEL PEMBELAJARAN PAIR CHECKS TERHADAP HASIL BELAJAR ILMU PENGETAHUN ALAM (IPA) DI KELAS V SDN 04 NANGA PINOH
}

\author{
Rini Kurniawati ${ }^{1}$, Rachmat Sahputra ${ }^{2}$ Kartini $^{3}$ \\ ${ }^{1}$ Mahasiswa Lulusan Program Studi PGSD Tahun 2017 \\ ${ }^{2}$ Dosen Universitas Tanjung Pura \\ ${ }^{3}$ Dosen STKIP Melawi \\ Jl. RSUD Melawi km. 04 Kec. Nanga Pinoh Kab. Melawi Kalimantan Barat \\ Jl. Prof. Dr. H. Hadari Nawawi, Bansir Laut, Kota Pontianak, Kalimantan Barat \\ Kurniawatirinisuho@gmail.com,Rahmat_ui@yahoo.com, \\ Kar.kamarudin88@gmail.com
}

\begin{abstract}
This study aims to determine how big the influence of learning model pair checks on science learning outcomes. Based on the results of observations and interviews conducted by researchers on 19-27 July 2017 researchers found students are less involved in the learning process because the model of learning in the teacher applied more focused on the book. This resulted in student learning outcomes are still under the KKM, of 26 students only 6 students who scored above the KKM and 20 students whose value is still below the KKM is equal 65. This research is an experimental research, pre-experimental type with One Group Pretest-Posttest design consisting of two meetings. Population in this research is all student of class V SDN 04 Nanga Pinoh, sample use saturated sample technique that is all member of population counted 26 student with details 12 female student and 14 male student. Variable in this research there are two that is independent variable is Pair Checks study model and dependent variable is result of study of science. Techniques and instruments of data collection in this research is a test by using a brief questionnaire consisting of 10 questions of pretest and 10 posttest questions and observation sheet of learning implementation of RPP. Data analysis techniques use written tests. Based on the results of the research note that the average implementation of RPP meeting I is 100\% and at the second meeting is $100 \%$. The average pretest is 51.15 and the posttest average is 78.07. So it can be known the difference is 26.92 average. Normality test shows that the value of sig $>0.05$ ie pretes $0.144>0.05$ and posttest $0.062>0.05$ can be concluded normal distributed data. Hypothesis test results obtained tcount $>$ ttable $(9.03>1.71)$ then $\mathrm{H} 0$ rejected and $\mathrm{H} 1$ accepted, based on the analysis results can be concluded that there is significant average influence before and after given treatment, That is there is influence from the use of learning model Pair Chechks on learning outcomes IPA students.
\end{abstract}

Keywords: Learning Outcomes, Pair Checks Learning Model, Ilmu Pengetahuan Alam (IPA).

Abstrak : Penelitian ini bertujuan untuk mengetahui seberapa besar pengaruh model pembelajaran pair checks terhadap hasil belajar IPA. Berdasarkan hasil observasi dan wawancara yang dilakukan peneliti pada tanggal 19-27 juli 2017 peneliti menemukan siswa kurang dilibatkan dalam proses pembelajaran dikarenakan model pembelajaran yang di terapkan guru lebih berfokus pada 
buku. Hal ini mengakibatkan hasil belajar siswa masih di bawah KKM, dari 26 siswa hanya 6 siswa yang memperoleh nilai di atas KKM dan 20 siswa nilainya masih di bawah KKM yaitu sebesar 65. Penelitian ini merupakan penelitian eksperimen, jenis pre-eksperimental dengan desain One Group Pretest-Posttest yang terdiri dari dua kali pertemuan. Populasi pada penelitian ini adalah seluruh siswa kelas V SDN 04 Nanga Pinoh, sampel menggunakan teknik sampel jenuh yaitu semua anggota populasi sebanyak 26 siswa dengan rincian 12 orang siswa perempuan dan 14 orang siswa laki-laki. Variabel pada penelitian ini ada dua yaitu variabel bebasnya adalah model pembelajaran Pair Checks dan variabel terikatnya adalah hasil belajar IPA. Teknik dan instrumen pengumpulan data pada penelitian ini adalah tes dengan menggunakan lembar soal isian singkat yang terdiri dari 10 soal pretest dan 10 soal posttest serta lembar observasi keterlaksanaan pembelajaran RPP. Teknik analisis data menggunakan tes tertulis. Berdasarkan hasil penelitian diketahui bahwa ratarata keterlaksanaan RPP pertemuan I yaitu $100 \%$ dan pada pertemuan II yaitu $100 \%$. Rata-rata pretest yaitu 51.15 dan rata-rata posttest yaitu 78.07. Sehingga dapat diketahui selisih rata-ratanya yaitu 26.92. Uji normalitas menunjukkan bahwa nilai sig $>0.05$ yaitu pretes $0.144>0.05$ dan posttest $0.062>0.05$ dapat disimpulkan data berdistribusi normal. Hasil uji hipotesis diperoleh $t_{\text {hitung }}>t_{\text {tabel }}(9.03>1.71)$ maka $\mathrm{H}_{0}$ ditolak dan $\mathrm{H}_{1}$ diterima, berdasarkan hasil analisis dapat disimpulkan bahwa terdapat pengaruh ratarata yang signifikan sebelum dan sesudah diberikan perlakuan, Artinya terdapat pengaruh dari penggunaan model pemeblajaran Pair Chechks terhadap hasil belajar IPA siswa.

Kata Kunci : Hasil Belajar, Model Pembelajaran Pair Checks, Ilmu Pengetahuan Alam (IPA).

Ousanto (2013: 167) sains atau IPA
adalah usaha manusia dalam

memahami alam semesta melalui

pengamatan yang tepat pada sasaran, serta

menggunakan prosedur, dan dijelaskan

dengan penalaran sehingga mendapatkan

suatu kesimpulan. Berdasarkan hasil

observasi dan wawancara dengan guru mata pelajaran Ilmu Pengetahuan Alam (IPA) siswa kelas V di SDN 04 Nanga

Pinoh pada tanggal 19, 24, 26 dan 27 Juli

2017 di temukan beberapa permasalahan

yang sering terjadi ketika proses

pembelajaran Ilmu Pengetahuan Alam

(IPA) berlangsung di dalam kelas.

Permasalahan yang dimaksud adalah kurangnya hasil belajar siswa dalam pembelajaran Ilmu Pengetahuan Alam (IPA). Nawawi (dalam Susanto, 2013: 5) yang menyatakan hasil belajar dapat diartikan sebagai tingkat keberhasilan siswa dalam mempelajari materi pelajaran di sekolah yang dinyatakan dalam skor diperoleh dari hasil tes mengenal sejumlah materi peljaran tertentu.

Melihat beberapa permasalahan yang terjadi di atas maka menurut peneliti permasalahan tersebut harus dicari solusinya agar proses pembelajaran Ilmu Pengetahuan Alam (IPA) bisa berjalan dengan baik di dalam kelas. Oleh karena itu untuk memperbaiki proses 
pembelajaran menjadi lebih baik, maka peneliti menggunakan model pembelajaran Pair Checks untuk memperbaiki hasil belajar siswa khususnya siswa kelas $\mathrm{V}$ SDN 04 Nanga Pinoh tersebut. Menurut Huda (2013: 211) menyatakan bahwa pair checks merupakan metode pembelajaran berkelompok antardua orang atau berpasangan yang dipopulerkan oleh Spencer Kagan pada tahun 1990. Model ini menerapkan pembelajaran kooperatif yang menuntut kemandirian dan kemampuan siswa dalam menyelesaikan persoalan. Metode ini juga melatih tanggung jawab sosial siswa, kerja sama, dan kemampuan memberi penilaian.

Berdasarkan penelitian yang pernah dilaksanakan oleh Yantiani pada tahun 2012 yang berjudul: "Pembelajaran Kooperatif Pair Checks Berpengaruh Terhadap Hasil Belajar Materi Bangun Ruang dan Bangun Datar Siswa Kelas IV Gugus IV Semarapura”, peneliti dapat mengetahui bahwa pengaruh model pembelajaran Pair Checks bisa dilaksanakan untuk melihat hasil belajar siswa.

Berdasarkan uraian di atas, peneliti mengambil kesimpulan bahwa untuk memperbaiki hasil belajar maka penelitian yang dilaksanakan ini adalah dengan menggunakan model pembelajaran Pair Checks. Model ini akan menjadi solusi yang tepat dari permasalahan yang 35| J P D, p-IS S N : 2252 -8156, e-IS S N : $2579-3993$ dihadapi oleh guru di SDN 04 Nanga Pinoh, khususnya pada mata pelajaran Ilmu Pengetahuan Alam (IPA) siswa kelas V. Selain itu, dengan model pembelajaran Pair Checks siswa akan belajar berkerjasama dan model ini juga melibatkan semua siswa saat proses pembelajaran, sehingga siswa menjadi aktif ketika belajar di kelas. Kemudian tujuan pembelajaran Ilmu Pengetahuan Alam (IPA) akan tercapai.

\section{METODELOGI PENELITIAN}

Penelitian ini menggunakan jenis pre-eksperimental. Desain yang digunakan dalam penelitian ini adalah One Groups Pretest-Posttest Design, yaitu eksperimen yang dilaksanakan dalam satu kelompok saja tanpa kelompok pembanding.

\begin{tabular}{|lll|}
\hline $\mathrm{O}_{1}$ & $\mathrm{X}$ & $\mathrm{O}_{2}$ \\
\hline
\end{tabular}

Gambar. 1 Desain one group pretest posttest (Arikunto, 2010: 212)

Hal pertama dalam pelaksanaan eksperimen menggunakan desain ini dilakukan dengan memberikan instrumen berupa soal isian singkat kepada sampel yang belum diberi perlakuan disebut pretest $\left(\mathrm{O}_{1}\right)$ untuk mengetahui hasil belajar siswa, setelah mendapatkan data hasil belajar siswa, maka selanjutnya dilakukan treatment (X) dengan model pembelajaran Pair Checks. Setelah adanya perlakuan kepada siswa, maka diberikan 
lagi instrumen berupa soal isian singkat posttest $\left(\mathrm{O}_{2}\right)$, instrumen ini untuk melihat hasil belajar IPA siswa sesudah diberikan treatment (X), dalam posttest akan didapat data hasil dari eksperimen dimana terdapat pengaruh hasil belajar siswa atau tidak sama sekali.

Populasi pada penelitian ini adalah seluruh subjek penelitian atau seluruh siswa kelas V SDN 04 Nanga Pinoh. Sampel yang dipilih peneliti adalah dengan menggunakan teknik sampel jenuh atau sampel total artinya sampel pada penelitian ini adalah satu kelas $\mathrm{V}$ SDN 04 Nanga Pinoh yang terdiri dari 26 siswa dengan rincian 14 orang siswa lakilaki dan 12 orang siswa perempuan. Variabel bebas pada penelitian ini adalah model pembelajaran Pair Checks. Variabel terikat dalam penelitian ini adalah hasil belajar siswa. Teknik dan instrumen pengumpulan data dalam penelitian ini adalah tes dengan menggunakan lembar soal isian singkat yang terdiri dari 10 soal pretest dan 10 soal posttest. Selain itu peneliti juga menggunakan Lembar Observasi keterlaksanaan RPP yang diisi oleh satu orang observer yaitu guru mata pelajaran IPA siswa kelas 04 Nanga pinoh.

Instrumen penilaian yang akan di uji adalah validitias isi. validitas isi ditentukan melalui pertimbangan ahli. Di dalam penelitian ini, pengujian reliabilitas Internal Consistency menggunakan
Cronbach's Alpha dengan menggunakan bantuan aplikasi SPSS 17. Pengujian reliabilitas Internal Consistensy dilakukan dengan cara mencoba instrumen sekali saja, kemudian data yang diperoleh dianalisis.

Analisis deskriptif dilakukan untuk mendeskripsikan data. Data pada penelitian ini berupa nilai pretest dan posttest hasil belajar siswa. Untuk mendeskripsikan data penelitian maka digunakan rumus untuk menghitung ratarata (mean). Untuk menguji hipotesis dalam penelitian ini uji statistik yang digunakan adalah uji t yaitu dimaksudkan untuk mengetahui apakah terdapat pengaruh rata-rata yang signifikan kemampuan awal sebelum dan setelah diberikan treatment.

$\mathrm{H}_{0}: \mu_{1}=\mu_{2} \quad$ (Tidak terdapat pengaruh rata-rata yang signifikan sebelum dan setelah diberikan perlakuan)

$\mathrm{H}_{1}: \mu_{1} \neq \mu_{2} \quad$ (Terdapat pengaruh ratarata yang signifikan sebelum dan setelah diberikan perlakuan).

\section{HASIL PENELITIAN}

Penelitian ini menggunakan validitas isi yang ditentukan melalui pertimbangan ahli. Instrumen penelitian ini telah diuji oleh satu orang guru mata pelajaran Ilmu Pengetahuan Alam (IPA) di SDN 04 Nanga Pinoh. Kemudian diuji oleh satu orang dosen ahli bahasa di STKIP Melawi, Pada tanggal 23 September 2017, 36| J P D, p - I S S N : 2252-8156, e - I S S N : $2579-3993$ 
instrumen berupa soal isian singkat diuji validitas oleh Ibu Halimatus, S.Pd. selaku guru mata pelajaran IPA di kelas V SDN 04 Nanga Pinoh, hasil dari uji validitas adalah validator menyarankan agar gambar pada soal lebih diperjelas lagi. Adapun skor validasi yang diberikan oleh Ibu Halimatus, S.Pd. adalah 93.75 sehingga instrumen pada penelitian ini sangat layak digunakan. Kemudian pada tanggal 25 September 2017, instrumen diuji validitas oleh Ibu Mastiah, S.S., M.Pd. selaku dosen ahli bahasa di STKIP Melawi. Skor yang diberikan oleh validator adalah 71.875 yang artinya instrument layak digunakan.

Dapat diketahui bahwa Df $=20$, dan $\mathrm{r}_{\text {hitung }}$ pretest $=0.435$ dan $\mathrm{r}_{\text {hitung }}$ posttest $=$ 0.419 sedangkan $r_{\text {tabel }}=0.36$. Maka dapat disimpulkan bahwa $r_{\text {hitung }}>r_{\text {tabel }}$ sehingga instrumen pada penelitian ini reliabel.

Berdasarkan hasil analisis dapat diketahui bahwa kegiatan pembelajaran yang dilaksanakan oleh peneliti di dalam kelas pertemuan I pada bagian kegiatan awal yaitu terlaksana $100 \%$, sedangkan pada bagian kegiatan inti mulai dari kegiatan eksplorasi, elaborasi, dan konfirmasi semuanya terlaksana $100 \%$, dan pada kegiatan penutup yaitu terlaksana $100 \%$ serta pada pertemuan I memiliki rata-rata keterlaksanaan RPP $100 \%$. Keterlaksanaan penelitian di dalam kelas pertemuan II pada bagian kegiatan awal yaitu terlaksana $100 \%$, sedangkan pada bagian kegiatan inti mulai dari kegiatan eksplorasi, elaborasi, dan konfirmasi semuanya terlaksana $100 \%$, dan pada kegiatan penutup yaitu terlaksana $100 \%$ serta pada pertemuan II memiliki rata-rata keterlaksanaan RPP $100 \%$.

Berdasarkan hasil penelitian diketahui bahwa sebelum menggunakan model pembelajaran Pair Checks (pretest) pada penelitian ini memperoleh skor dengan angka terendah yaitu 20 dengan inisial JL dan angka tertinggi yaitu 80 dengan inisial CA, kemudian setelah menggunakan model pembelajaran Pair Checks (posttest) pada penelitian ini memperoleh skor dengan angka terendah yaitu 50 dengan inisial JL serta angka tertinggi yaitu dua orang siswa yang mendapat nilai 100 dengan inisial AS dan LL. Berdasarkan dari analisis rata-rata hasil pretest dan rata-rata hasil posttest, maka dapat diketahui bahwa rata-rata pretest adalah 51.15 , dan rata-rata posttest adalah 78.07 hal ini menunjukan bahwa adanya (selisih) rata-rata yang signifikan sebelum dan sesudah perlakuan yaitu sebesar 26.92 .

\section{Hasil Uji Normalitas}

Dapat diketahui bahwa hasil uji normalitas data pretest mendapat nilai signifikan $0.144>0.05$ yang berarti data berdistribusi normal. Sedangkan, hasil uji normalitas posttest mendapat nilai 
signifikan $0.062>0.05$ yang berarti data berdistribusi normal.

\section{Hasil Uji Hipotesis}

Uji hipotesis dalam penelitian ini dilakukan dengan menggunakan uji t. Apabila jumlah $t_{\text {hitung }} \leq t_{\text {tabel, }}$, berarti hipotesis $\mathrm{H}_{0}$ di terima dan $\mathrm{H}_{1}$ ditolak, dan jika jumlah $t_{\text {hitung }} \geq t_{\text {tabel, }}$, berarti $\mathrm{H}_{0}$ ditolak dan $\mathrm{H}_{1}$ diterima. Dari hasil analisis dapat diketahui bahwa $t_{\text {tabel }}$ dalam penelitian ini adalah 1.71. Oleh sebab itu kita bisa mengetahui bahwa $t_{\text {hitung }}>t_{\text {tabel }}$ dengan angka 9.03>1.71, maka $\mathrm{H}_{0}$ ditolak dan $\mathrm{H}_{1}$ diterima, sehingga dapat disimpulkan bahwa adanya perbedaan rata-rata yang signifikan sebelum dan sesudah diberikan perlakuan. Artinya terdapat pengaruh setelah menggunakan model pembelajaran Pair Checks terhadap hasil belajar siswa.

\section{Pembahasan}

Pengujian reliabelitas instrumen soal pretest dapat diketahui bahwa $\mathrm{r}_{\text {hitung }}=$ 0.435, dan $r_{\text {tabel }}=0.34$ dan pengujian reliabelitas instrumen soal posttest yaitu $r_{\text {hitung }}=0.419$, dan $r_{\text {tabel }}=0.36$. Maka dapat disimpulkan bahwa $r_{\text {hitung }}>r$ tabel, sehingga instrument soal pretest dan posttest pada penelitian ini reliabel. Dari lembar keterlaksanaan RPP dapat diketahui bahwa kegiatan pembelajaran yang dilaksanakan oleh peneliti di dalam kelas pertemuan I dan pertemuan ke II memiliki skor yang sama yaitu pada bagian kegiatan awal terlaksana $100 \%$, serta pada bagian kegiatan inti mulai dari kegiatan eksplorasi, elaborasi, dan konfirmasi semuanya juga terlaksana $100 \%$, dan pada kegiatan penutup yaitu terlaksana $100 \%$ serta pertemuan I dan II memiliki rata-rata keterlaksanaan RPP 100 \%. Berdasarkan dari analisis rata-rata hasil pretest dan ratarata hasil posttest, maka dapat diketahui bahwa rata-rata pretest adalah 51.15, dan rata-rata posttest adalah 78.07 hal ini menunjukan bahwa adanya (selisih) ratarata yang signifikan sebelum dan sesudah perlakuan yaitu sebesar 26.92. Hasil uji normalitas data pretest mendapat nilai signifikan $0.144>0.05$ yang berarti data berdistribusi normal. Sedangkan, hasil uji normalitas posttest mendapat nilai signifikan $0.062>0.05$ yang berarti data berdistribusi normal.

Pengujian hipotesis hasil pretest dan posttest menunjukan bahwa $t_{\text {hitung }}>$ $\mathrm{t}_{\text {tabel }}$ dengan angka 9.03>1.71, maka $\mathrm{H}_{0}$ ditolak dan $\mathrm{H}_{1}$ diterima, sehingga dapat disimpulkan bahwa adanya perbedaan ratarata yang signifikan sebelum dan sesudah diberikan perlakuan. Artinya terdapat pengaruh setelah menggunakan model pembelajaran Pair Checks terhadap hasil belajar siswa.

\section{SIMPULAN}

Berdasarkan hasil penelitian diketahui setelah dilakukan analisis diperoleh rata-rata skor pada pretest adalah sebesar adalah 51.15, serta rata-rata skor 38| J P D, p - I S S N : 2252 - 8156 , e - I S S N : 2579 - 3993 
pada posttest adalah 78.07 dan selisih rataratanya adalah 26.92. Selain itu juga dapat dilihat dari pengujian hipotesis dengan hasil pretest dan posttest menunjukan bahwa $t_{\text {hitung }}>\mathrm{t}_{\text {tabel }}(9.03>1.71)$ maka $\mathrm{H}_{0}$ ditolak dan $\mathrm{H}_{1}$ diterima, sehingga dapat diketahui bahwa adanya perbedaan ratarata yang signifikan sebelum dan sesudah diberikan perlakuan. Artinya terdapat pengaruh setelah menggunakan model pembelajaran Pair Checks terhadap hasil belajar IPA siswa kelas V SDN 04 Nanga Pinoh. Berdasarkan hasil uji hipotesis maka dapat disimpulkan bahwa penelitian yang dilaksanakan ini berhasil.

\section{DAFTAR PUSTAKA}

Anuar. 2014. Upaya meningkatkan hasil belajar ilmu pengetahuan Alam (IPA) menggunakan model cooperatif tife pair cheks pada siswa kelas V SDN 06 Tanjung Sokan. Jurnal pendidikan dasar. Volume 2 nomor 1 Tahun 2014. Program Studi PGSD: STKIP Melawi.

Arikunto, S. 2010. Prosedur Penelitian. Jakarta: Rineka Cipta.

Haniah, N. 2013. Statistika Pendidikan. (Online) Tersedia di http://Statistika Pendidikan.Com. Diakses 20 Mei 2017.

Huda, M. 2013. Model-model Pengajaran dan Pembelajaran. Yogyakarta. Pustaka Pelajar.

Susanto, A. 2013. Teori Belajar dan Pembelajaran di Sekolah Dasar. Jakarta: Kencana Prenada Media Group.

Yantiani. 2013. Pembelajaran Kooperatif Pair Checks Berpengaruh Terhadap Hasil Belajar Materi Bangun Ruang dan Bangun Datar Siswa Kelas IV Gugus IV Semarapura. (Online) Tersedia di http://pembelajaran kooperatif/2012/06/17/html. Diakses 29 Mei 2017. 